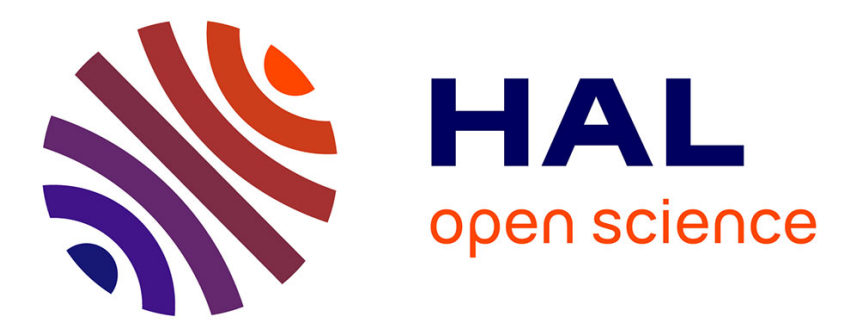

\title{
Quantitative infrared thermography applied to blow moulding process: measurement of a heat transfer coefficient
}

Serge Monteix, Yannick Le Maoult, Fabrice Schmidt, Jean Paul Arcens

\section{- To cite this version:}

Serge Monteix, Yannick Le Maoult, Fabrice Schmidt, Jean Paul Arcens. Quantitative infrared thermography applied to blow moulding process: measurement of a heat transfer coefficient. Quantitative InfraRed Thermography Journal, 2004, 1 (2), pp.133-150. 10.3166/qirt.1.133-150 . hal-02050658

\section{HAL Id: hal-02050658 \\ https://imt-mines-albi.hal.science/hal-02050658}

Submitted on 27 Feb 2019

HAL is a multi-disciplinary open access archive for the deposit and dissemination of scientific research documents, whether they are published or not. The documents may come from teaching and research institutions in France or abroad, or from public or private research centers.
L'archive ouverte pluridisciplinaire HAL, est destinée au dépôt et à la diffusion de documents scientifiques de niveau recherche, publiés ou non, émanant des établissements d'enseignement et de recherche français ou étrangers, des laboratoires publics ou privés. 


\title{
Quantitative infrared thermography applied to blow moulding process: measurement of a heat transfer coefficient
}

\author{
Serge Monteix* — Yannick Le Maoult** — Fabrice Schmidt** \\ — Jean Paul Arcens **
}

* Philips Special Lighting, Pont à Mousson Factory, Chemin de Montrichard, BP 149, 54705, Pont à Mousson Cedex, France.

Serge.monteix@philips.com.

** Cromep, Ecole des Mines d'Albi Carmaux, Campus Jarlard, Route de Teillet, 81013 ALBI Cedex 09, France.

lemaoult@enstimac.fr, corresponding author.-Schmidt@enstimac.fr -

arcens@enstimac.fr

ABSTRACT: This paper deals with the heat conditioning stage of blow moulding process applied to P.E.T bottles forming. One of the most important stage of this process is the radiative heating stage which is performed with infrared ovens using powerful halogen lamps. To validate a 3D control volume thermal software, called Plastirad, developed in our laboratory, temperatures maps were needed on the plastic preforms as well as convective heat transfer coefficient inside the oven. This measurement has been performed with two different methods : IR thermography and hot wire anemometry. These two methods are investigated and the main results are compared to focus on the interest of IR thermography.

KEY WORDS: blow moulding, IR camera, semi-transparent material, convection coefficient, anemometry 


\section{Introduction}

The industrial injection stretch-blow moulding process of Polyethylene Terephtalate or P.E.T bottles (Rosato 89) requires a heating step prior forming. During this step, the amorphous preform corresponding to the form prefiguring the final bottle geometry is heated from the ambient temperature to the forming temperature between 105 to $115^{\circ} \mathrm{C}$. Due to the weak polymers thermal conductivity $(0.25 \mathrm{~W} / \mathrm{m} . \mathrm{K})$ and very high production rate (up to 40,000 bottles per hour); for the P.E.T, the heating step is made using infrared ovens (Monteix, 2001). These oven are constituted with a row of special halogen-lamps, which permit a rapid heating with high flux intensities $\left(300-400 \mathrm{~kW} / \mathrm{m}^{2}\right)$ and a cooling fan to control the external surface temperature and to avoid the thermal crystallisation which would make the transparent amorphous preform completely opaque and more fragile. Then, the ventilation appears as a key parameter controlling the preform temperature distribution. Our investigation deals with the measurement of this heat transfer coefficient using the experimental set-up we reproduced from the industrial machine to the laboratory scale. To do this, two methods were used: one based on measurements made on the preform surface with an IR camera, the other using conventional anemometer technology to measure the air velocity and temperature. Then comparison of these two methods is analysed and discussed.

\section{Experimental set-up}

Figure 1 shows the experimental set-up developed in our laboratory, constituted with six halogen lamps (Philips $1 \mathrm{~kW}-235 \mathrm{~V}$ ) and a flat aluminium reflector located behind the lamps. The cooling fan disposed opposite to the lamps is enclosed inside an aluminium box and the flow produced by the fan passes through a set of slits and is blown onto the preform surface placed normally to the air jet. Due to the smooth aspect of the aluminium box, we consider this part of the set-up as a secondary infrared reflector. The preform, $100 \mathrm{~mm}$ height and $25 \mathrm{~mm}$ in diameter (Fig. 1), can rotate axially in the middle of the oven, this point is of prime importance for a uniform heating through the preform circumference. However the narrowness of this experimental set-up leads to instrumentation difficulties for the different sensing probes.

\section{Heat transfer coefficient computation using an infrared camera.}

\subsection{Parameters influencing the measurement accuracy using an infrared camera and the P.E.T preform.}

The heat flux received by the camera is related to the radiative properties of the materials observed; here, the P.E.T preform but any elements in the thermal scene (Fig. 2) such as reflectors, lamps can contribute to the total heat flux integrated by the camera. 


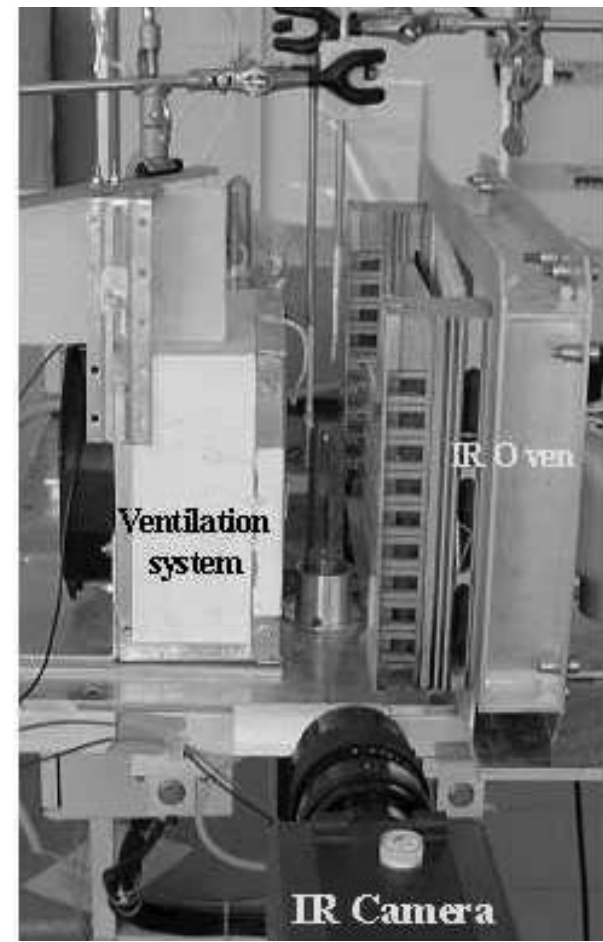

a) General view of the oven

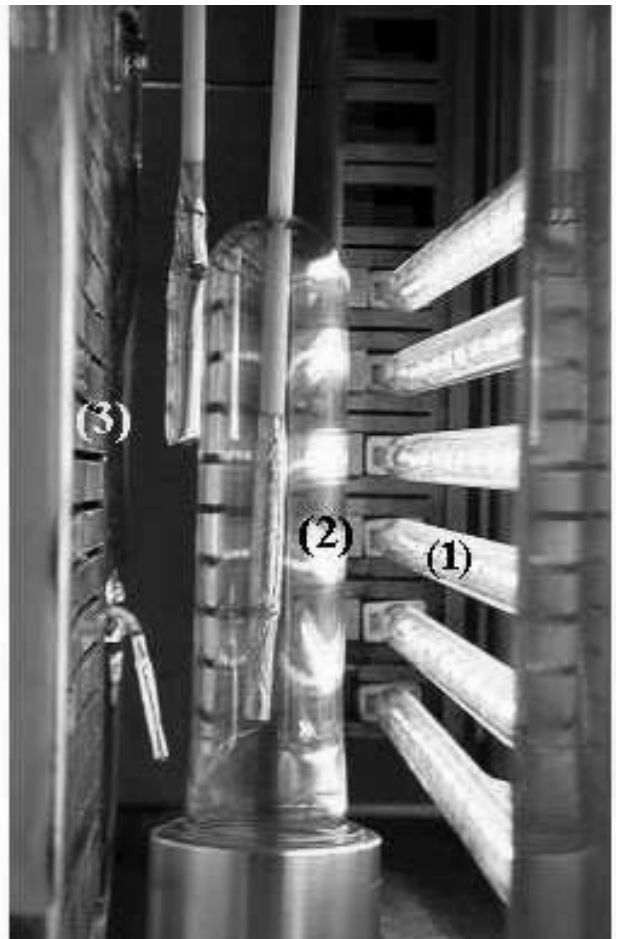

b) Details: 1) halogen lamp,

2) preform, 3) ventilation slits

Figure 1. Experimental set-up and infrared oven

Thus, precautions are needed in order to measure the real temperature of the preform with a good accuracy. So we had to describe the environment participation; this can be achieved, at first, by the radiometric equation .

$$
V^{0}\left(T_{e q}\right)=\tau_{a t m}\left(T_{a t m}\right) \cdot\left(\varepsilon_{p r e f} \cdot V^{0}\left(T_{p r e f}\right)+\rho_{p r e f} \cdot V^{0}\left(T_{e n v}\right)\right)
$$

In equation [1], $\mathrm{V}^{0}\left(\mathrm{~T}_{\mathrm{eq}}\right)$ corresponds to the camera output voltage; $\mathrm{T}_{\mathrm{eq}}$, the temperature corresponding to an equivalent blackbody temperature obtained with the system calibration; $\tau_{\mathrm{atm}}$, the atmosphere transmission coefficient between the preform and the camera. This coefficient is assumed to be equal to one in our application due to the very short distance between the camera and the preform : about $0.5 \mathrm{~m} ; \varepsilon_{\text {pref }}$ and $\rho_{\text {pref }}$ are respectively the emissivity and reflectivity of the P.E.T preform integrated over the spectral band of the camera chosen for the measurement. This implies a study of these two parameters to choose the more relevant spectral band. $T_{\text {pref }}$ is the real preform temperature and $T_{\text {env }}$, the equivalent blackbody environment temperature. 


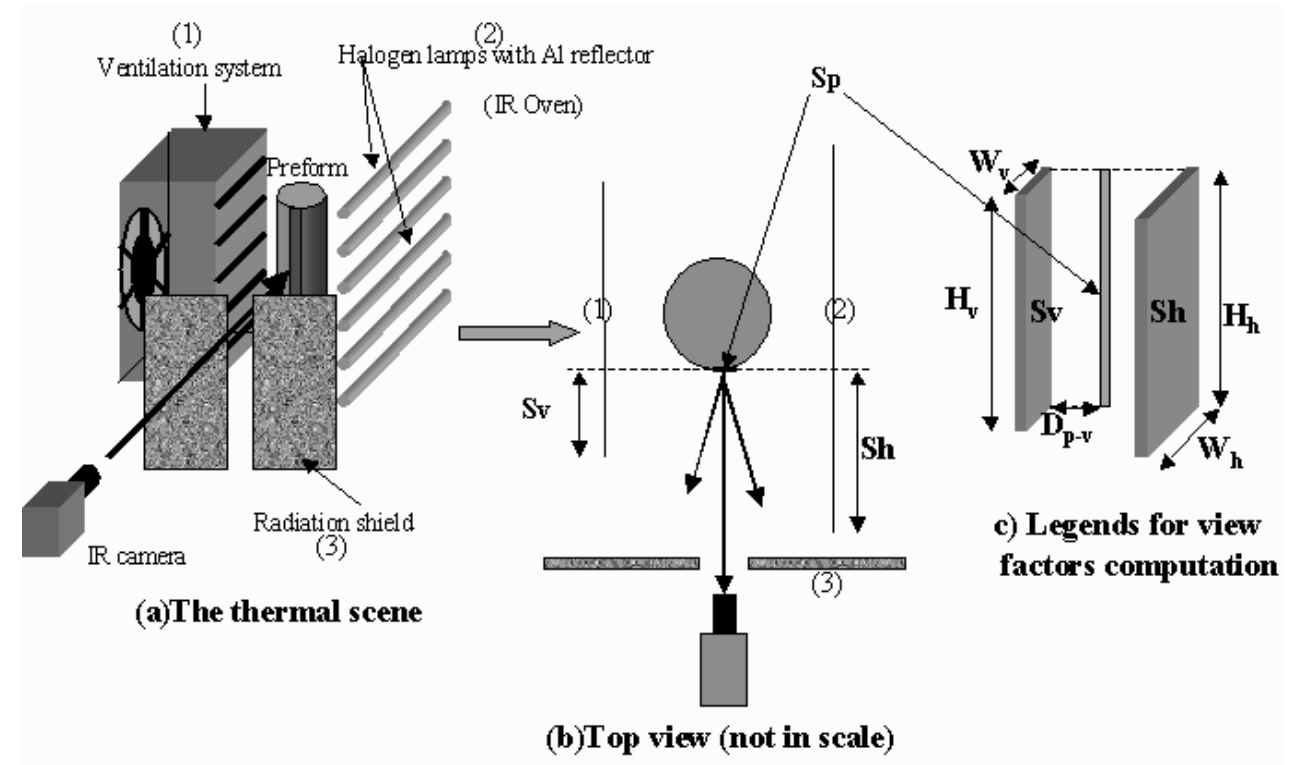

Sp : Selectea area (vertical strip) on the preform for the temperature measurements.

Sv: Restricted ventilation support area visible by $\mathrm{Sp}$

Sh : Restricted halogen lamps area visible by $\mathrm{Sp}$

Figure 2. The thermal scene viewed from the infrared camera

\subsection{The choice of the optimal spectral band for the measurements.}

P.E.T spectral properties measurements were obtained using 3-mm thick sheets. These sheets were obtained by injection moulding in the same conditions than tubular preforms. Differential scanning calorimetry tests (DSC) were carried out in order to measure the sheets crystallinity. Samples of 10-15 mg weight were cut away from the thick sheet. The DSC tests were performed on a Mettler calorimeter at a heating rate of $10^{\circ} \mathrm{C} / \mathrm{min}$. The average crystallinity value of these measurements was about $5 \%$, corresponding to an amorphous P.E.T as well as experiments performed on tubular preforms, which confirms that diffusion of the radiation can be neglected. Then the P.E.T spectral properties measurements have been made using a PerkinElmer FT-IR spectrometer for the range of wavelengths $\lambda$ in $[1-25] \mu \mathrm{m}$. The initial $3 \mathrm{~mm}$ thick sheets were polished in order to obtain samples of $0.3 \mathrm{~mm}$ thickness. We assumed in agreement with (Weinand 87) that these properties are independent of the temperature variation. From apparent transmission measurements $\mathrm{Ta}_{\lambda}$ for the range of thickness [0.3-3 mm] and (Howell 92), we get :

$$
T a_{\lambda} \approx \tau_{\lambda} \cdot \frac{1-\rho_{\lambda}}{1+\rho_{\lambda}} \quad \text { and } \quad \tau_{\lambda}=e^{-K a \lambda . d}, \text { i.e }-\ln \left(T a_{\lambda}\right)=K_{a \lambda} \cdot d+\ln \left(\frac{1+\rho_{\lambda}}{1-\rho_{\lambda}}\right)
$$


These measurements lead to an intrinsic absorption coefficient $\mathrm{K}_{\mathrm{a} \lambda}$ independent of $\mathrm{d}$ (Beer's law is relevant) and reveal that P.E.T presents successively transparent and opaque region over large spectra between 1 to $25 \mu \mathrm{m}$ (Lebaudy, 89), (Monteix et al., 2001). We have then computed the Planck's mean absorption coefficient with [3] :

$$
K_{a}(T=400 K)=\frac{\int_{\Delta \lambda_{i}} K_{a \lambda} \cdot I_{\lambda, b}\left(\lambda, T_{400 K}\right) d \lambda}{\int_{\Delta \lambda_{i}} I_{\lambda, b}\left(\lambda, T_{400 K}\right) d \lambda}
$$

$\mathrm{T}=400 \mathrm{~K}$ is the classical processing temperature of the perform and $\mathrm{I}_{\lambda \mathrm{b}}$ the spectral distribution of blackbody emission. Equation [3] gives $K_{a}(T)=200 \mathrm{~m}^{-1}$ for $\Delta \lambda_{i}=[1-$ $3 \mu \mathrm{m}]$ region, $4000 \mathrm{~m}^{-1}$ in the $[3-5 \mu \mathrm{m}]$ region and $30000 \mathrm{~m}^{-1}$ in the $[5-20 \mu \mathrm{m}]$ region. Using the optical thickness $K_{a} \cdot d$, and $K_{a} \cdot d=1$, we got a photon mean free path $d=$ $1 / \mathrm{K}_{\mathrm{a}}$ to be compared to the thickness of the preform $(3 \mathrm{~mm})$ : respectively $\mathrm{d}=5 \mathrm{~mm}$ for the $[1-3 \mu \mathrm{m}]$ region, $\mathrm{d}=0.25 \mathrm{~mm}$ for the $[3-5 \mu \mathrm{m}]$ region and $30 \mu \mathrm{m}$ for the $[5-20$ $\mu \mathrm{m}]$ region. This last value corresponds to an opaque material for which radiation come only from the material surface. It means correction used by (Hajji et al., 1994) for semitransparent polymers are not required here and measurements using a Long Wave spectral band [8-12 $\mu \mathrm{m}]$ are surface temperature measurements. For this reason, we have chosen an AGEMA 880 Long Wave infrared camera connected to a real time 12 bits thermography software among the three systems we get in Ecole des Mines: Very Short Wave (VSW) [0.75-1.1 $\mu \mathrm{m}]$, Short Wave [3-5 $\mu \mathrm{m}](\mathrm{SW})$ and Long Wave (LW). The corresponding values of emissivity and reflectivity calculated for the radiometric equation [1] in order to compute the real preform temperature are respectively $\varepsilon=0.93$ and $\rho=0.07$. Then the camera was calibrated versus the temperature using a Land blackbody between $30^{\circ} \mathrm{C}$ and $175^{\circ} \mathrm{C}$ corresponding to the full window of the phenomenon we wanted to observe. Ten points over this range were recorded and led to an accuracy better than $0.5^{\circ} \mathrm{C}$ in comparison with the blackbody reference temperature.

\subsection{Oven environment influence on the IR measurements: a first approach.}

To control the temperature measurement of the preform inside the oven, we have firstly estimated the different irradiances incoming to the lens of the camera from the different areas of the oven, mainly :

E1 : irradiance received by the camera from the preform

E2 : irradiance received by the camera from the quartz tube and reflected by the preform

E3 : irradiance received from the ventilation system and reflected by the preform.

Assuming that all surfaces are diffuse for reflection and emission, composed of grey materials, the different terms, neglecting the atmosphere absorption and multiple reflections are given by : 


$$
\begin{aligned}
& E_{1}=\frac{\phi_{\text {pref }}}{S_{c}}=\frac{S_{p} \varepsilon_{p} \sigma T_{p}^{4} f\left(\Delta \lambda, T_{p}\right)}{S_{c}} F_{p-c} \\
& E_{2}=\frac{\phi_{\text {plamp }} s}{S_{c}}=\frac{\rho_{p}\left(S_{Q} \varepsilon_{Q} \sigma T_{Q}^{4} f\left(\Delta \lambda, T_{Q}\right) F_{Q-p}\right)}{S_{c}} F_{p-c} \\
& E_{3}=\frac{\phi_{v}}{S_{c}}=\frac{\rho_{p}\left(S_{v} \varepsilon_{v} \sigma T_{v}^{4} f\left(\Delta \lambda, T_{v}\right) F_{v-p}\right)}{S_{c}} F_{p-c}
\end{aligned}
$$

and $\mathrm{E}_{\mathrm{t}}=\mathrm{E}_{1}+\mathrm{E}_{2}+\mathrm{E}_{3}$ is the total irradiance seen by the camera. $f(\Delta \lambda, \mathrm{Tp})$ corresponds to the fraction of radiation emitted between the two wavelengths $\lambda_{1}$ and $\lambda_{2}$, here: 8 and $12 \mu \mathrm{m}$. These expressions depend also on geometric interaction depicted by view factors computation $\mathrm{F} ; \mathrm{S}_{\mathrm{c}}$ is the input surface of camera lens, $\mathrm{S}_{\mathrm{Q}}$ is an equivalent area corresponding to the halogen lamps, $S_{V}$ is the effective area of the ventilation support, $\mathrm{S}_{\mathrm{P}}$ the effective area of the preform and $\mathrm{F}_{\mathrm{i}-\mathrm{j}}$ are the different view factors between lamps, preform and ventilation support (example: $\mathrm{F}_{\mathrm{Q}-\mathrm{P}}$ is the view factor between lamps and the preform). In each case, to compute these view factor using analytical formulation (Siegel et al.,1992), the real geometry is replaced by an elementary one (figure 2c). These assumptions lead to the computation of simple view factors between two rectangles with dimensions reported in table 1 .

Then, with [4], we compared the relative contributions of each term to the total irradiance. The irradiance of each source were computed versus its own temperature (table 2) considering maximum value at the cooling system restart.

\begin{tabular}{|c|c|c|c|c|}
\hline Geometry & $\begin{array}{c}\mathrm{W} \\
(\mathrm{mm})\end{array}$ & $\begin{array}{c}\mathrm{H} \\
(\mathrm{mm})\end{array}$ & $\begin{array}{c}\text { Distance/preform } \\
(\mathrm{mm})\end{array}$ & View factor \\
\hline Preform & 5 & 100 & 0 & \\
\hline 6 halogen lamps system & 122.5 & 100 & 34 & FQ-p $=0.989 .10^{-3}$ \\
\hline Cooling system & 86.5 & 100 & 34 & Fv-p $=0.127 .10^{-2}$ \\
\hline
\end{tabular}

Table 1. Dimension of the thermal scene for analytical computation of view factors

\begin{tabular}{|c|c|c|}
\hline Radiative source & $\mathrm{T}(\mathrm{K})$ & Comment \\
\hline Preform & 373 & $\begin{array}{c}\text { Average temperature measurement; after the cor- } \\
\text { responding heating step and during natural cooling }\end{array}$ \\
\hline $\begin{array}{c}\text { 6 halogen lamps : } \\
\text { quartz temperature }\end{array}$ & 730 & $\begin{array}{c}\text { Current temperature computed during halogen lamps } \\
\text { running. Certainly higher than during the cooling } \\
\text { stage }\end{array}$ \\
\hline Cooling system & 320 & $\begin{array}{c}\text { From thermocouples stickled over the ventilation } \\
\text { support and shielded inside aluminium cavity }\end{array}$ \\
\hline
\end{tabular}

Table 2. Temperature values of direct and indirect radiative sources 


\begin{tabular}{|c|c|c|}
\hline $\begin{array}{c}\text { Radiative } \\
\text { source }\end{array}$ & Properties $[8-12] \mu \mathrm{m}$ & Source of Data \\
\hline Preform & $\varepsilon=0.93, \rho=0.07$ & measurements \\
\hline the 6 lamps & $\varepsilon=0.82$ & (Monteix, 2001) \\
\hline $\begin{array}{c}\text { Cooling } \\
\text { sytem }\end{array}$ & $\varepsilon=0.52$ & $\begin{array}{c}\text { Measurement at } 45^{\circ} \mathrm{C} \text { using the camera } \\
\text { and a black body at } 100^{\circ} \mathrm{C}\end{array}$ \\
\hline
\end{tabular}

Table 3. Radiative properties of thermal sources

\begin{tabular}{|c|c|c|}
\hline Radiative source & Ei W/ $/ \mathrm{m}^{2}[8-12] \mu \mathrm{m}$ & $\mathrm{Ei} / \mathrm{Et}(\%)$ \\
\hline Preform & 0.019 & $92.2 \% /$ direct \\
\hline 6 halogen lamps system & 0.0016 & $7.6 \%$, reflection \\
\hline Cooling system & $4.03 \mathrm{E}-5$ & $0.2 \%$, reflection \\
\hline
\end{tabular}

Table 4. Estimation of the different irradiances received by the camera

The optical properties in [8-12] $\mu \mathrm{m}$ are reported in Table 3 and comparisons in table 4.

These comparisons lead to conclude that the oven environment contributions are negligible. Using [4], we have simulated, on figure 3, the equivalent blackbody temperatures in the different cases : superimposing the blackbody reference and the irradiance received by the camera with all the perturbation $\left(E_{t}=E_{1}+E_{2}+E_{3}\right)$ without any correction (assuming the preform is a black body) and then taking into account the optical P.E.T properties and an environment temperature equal to $25^{\circ} \mathrm{C}$. This computation leads to a discrepancy of $1{ }^{\circ} \mathrm{C}$ for a $120^{\circ} \mathrm{C}$ preform temperature reference (figure 3 ).

This numerical approach has been compared to experimental data; a sequence of images has been recorded when the preform was just entering inside the oven : it was possible to measure a new equivalent blackbody temperature related to the cumulated reflections on the preform just before heating. This temperature was close to $28^{\circ} \mathrm{C}$. The difference between the new and default environment temperature $\left(25^{\circ} \mathrm{C}\right)$ is $3^{\circ} \mathrm{C}$, slightly different from the computed value $\left(1^{\circ} \mathrm{C}\right)$, but we assumed that a correction was not necessary. 


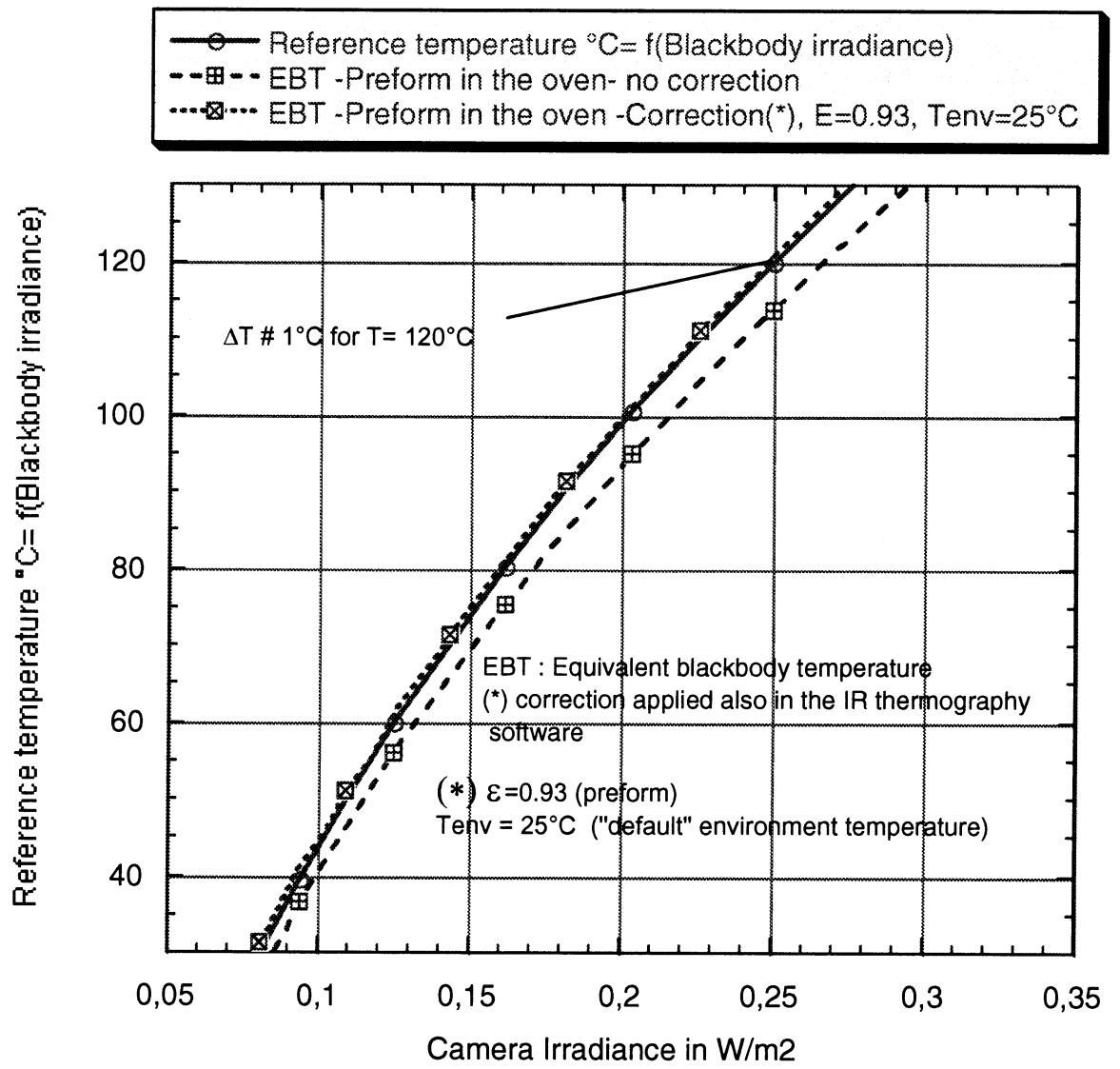

Figure 3. Equivalent blackbody temperatures.

\subsection{Measurement of the heat transfer coefficient-methodology}

The computation of the heat transfer coefficient distribution along the preform height is based on the IR images acquisition (Figure 4).

The acquisition rate was equal to one image per second for a preform in rotation inside the oven. More particularly we dealt with the spatial average temporal temperature variation over 7 circular zones regularly disposed along the preform height. Here, each circular zone had a diameter of $5 \mathrm{~mm}$, this size is a compromise between an area large enough to check the homogeneity of temperatures and spatial resolution of our camera. Then three steps are required for the measurement :

- The first step : a 20 s heating stage which permits to get a sufficient preform temperature; the ventilation system is on to avoid the crystallisation of the perform surface. 


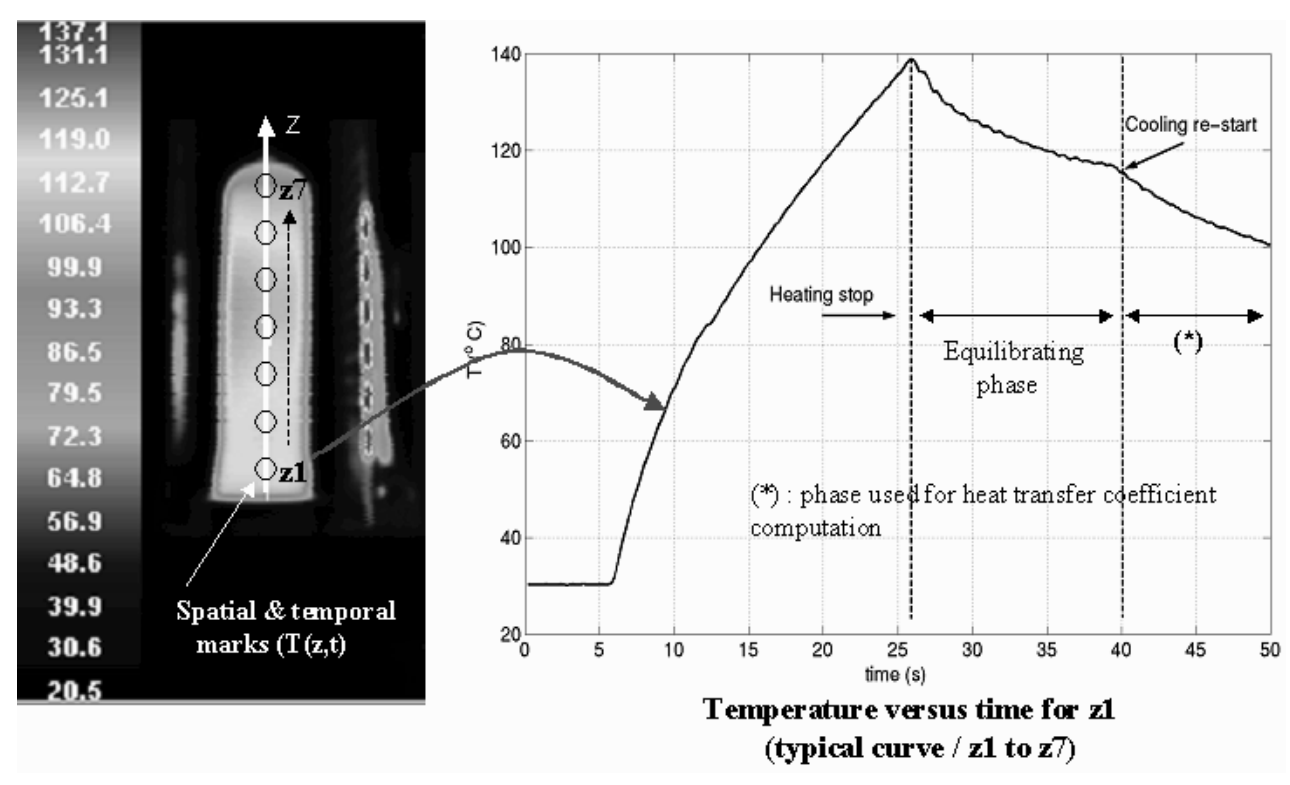

Figure 4. Areas of interest and methodology

- The second step : an equilibrating phase of $10 \mathrm{~s}$ is applied to leave the preform temperature evolve freely due to conduction, radiation and natural convection in order to tend to a zero gradient through its thickness.

- The third step : the ventilation is switched on. We analysed more particularly this phase.

The 10s equilibrating step we have imposed to the preform was shown to be appropriate by measurements of the inner and outer preform temperature (Monteix et al., 2001).

Applying these conditions, we assumed that, at the ventilation restart, the preform presented for each measurement target along its height, a uniform temperature through the thickness corresponding to the surface temperature at this time. In this scope, we have chosen to analyse the temperature distribution using a transient one-dimensional semi-infinite analytical model (DeVriendt, 1984) through the preform thickness by solving the following equation :

$$
\frac{\partial^{2} T}{\partial x^{2}}=\frac{1}{\alpha} \frac{\partial T}{\partial t}
$$

with the following initial and boundary conditions : 


$$
T(x, t=0)=T_{i n i} ;-\lambda\left(\frac{\partial \mathrm{T}}{\partial x}\right)_{x=0}=h_{g}\left(T_{\infty}-T(0, t)\right) \quad ; T(\mathrm{x}=\infty, \mathrm{t})=\mathrm{T}_{\mathrm{ini}}
$$

$T_{i n i}$ is the initial temperature of the perform at the beginning of the cooling and $T_{\infty}$ the temperature of the air far away from the perform. Finally, solving this equation leads to the temperature relation ship for temperature versus time t, thickness $\mathrm{x}$ and $\mathrm{h}$ :

$$
\frac{T(x, t)-T_{i n i}}{T_{\infty}-T_{i n i}}=\operatorname{erfc}\left(\frac{x}{2 \sqrt{\alpha t}}\right)-\left[e^{\left(\frac{\lg x}{\lambda}+\frac{h^{2} \alpha t}{\lambda^{2}}\right)} \cdot \operatorname{erfc}\left(\frac{x}{2 \sqrt{\alpha t}}+\frac{h_{g} \sqrt{\alpha t}}{\lambda}\right)\right]
$$

where $\alpha$ is the thermal diffusivity of the material and here, $\lambda$ its thermal conductivity. For P.E.T these values are $\alpha=1.4 .10^{-7} \mathrm{~m}^{2} . \mathrm{s}^{-1}$ and $\lambda=0.25 \mathrm{~W} / \mathrm{m} . \mathrm{K}$. In this case, the heat transfer coefficient $h_{\mathrm{g}}$ is the amount of the radiative and convective transfer. The convective part is obtained after subtracting the radiative one and is given by :

$h_{c}=h_{g}-h_{r}=\mathrm{h}_{\mathrm{g}}-\varepsilon \sigma \frac{\left(\bar{T}^{4}-T_{e n v}{ }^{4}\right)}{\bar{T}-T_{e n v}}$,

where $\mathrm{T}_{\mathrm{env}}$ is a radiative environment temperature.

\subsection{One-dimensional analytical model accuracy}

Since the preform geometry corresponds to a cylinder, the approach used is a rough assumption and to evaluate the resulting discrepancy, we have compared temperature computations from this one-dimensional model to ones issued from a 3D Control Volume Model (CVM) using "Plastirad" software dealing in this last case with a tubular geometry of $3 \mathrm{~mm}$ thickness close to the preform one. More particularly, we compared temperature evolution, during a cooling step, from a uniform initial temperature, due to three different heat transfer coefficients of 5,35 and $65 \mathrm{~W} \mathrm{~m}^{-2} \mathrm{~K}^{-1}$. We have also taken into account the same P.E.T properties and a constant environment temperature $\mathrm{T}_{\text {env }}$ equal to $30^{\circ} \mathrm{C}$. We have superimposed on figure 5 the external surface temperature $T_{\text {ext }}$ and the internal one $T_{\text {int }}$ at a $3 \mathrm{~mm}$ depth versus the time for the greatest value of $h_{g}$.

We can notice that, for the internal temperature, a difference is noticeable between CVM and 1D computation for a time close to $\sim 7 \mathrm{~s}$. This time corresponds, for the thickness e equal to $3 \mathrm{~mm}$, when the surface perturbation is viewed at $1 \%$ on the internal surface of the preform, which leads to (DeVriendt 1984), $\mathrm{t} \sim\left(\mathrm{e}^{2} / 13.24\right.$ $\alpha) \sim 7 \mathrm{~s}$. This divergence is well described by the CVM. To quantify the discrepancy between the two approaches, we have computed the relative difference for each time step and from these value we have computed the average relative difference versus the time for each h (Table 5). 


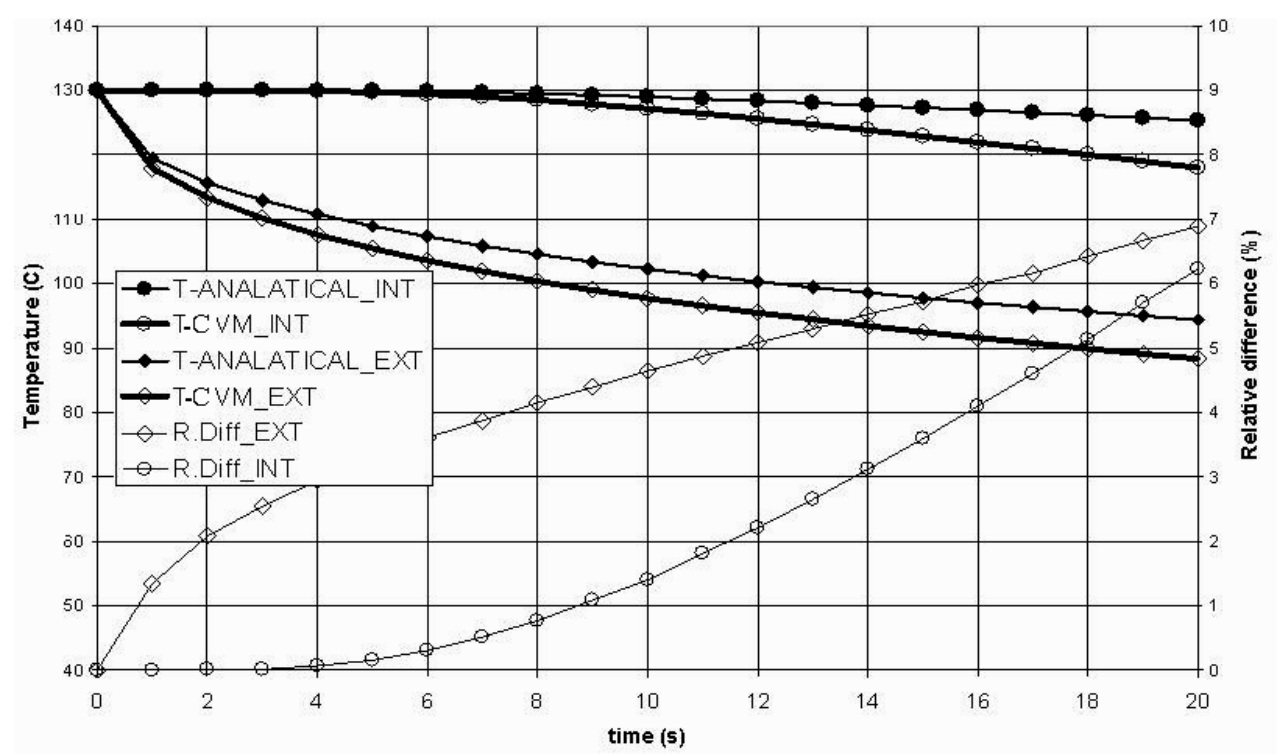

Figure 5 . 1D temperatures computation and CVM; $h_{g}=65 \mathrm{~W} \mathrm{~m}^{-2} \mathrm{~K}^{-1}$

\begin{tabular}{|c|c|c|}
\hline hg $\left(\mathrm{W} \mathrm{m}^{-2} \mathrm{~K}^{-1}\right)$ & Error / T_int (\%) & Error / T_ext (\%) \\
\hline 5 & 1.1 & 0.7 \\
\hline 35 & 2.9 & 1.8 \\
\hline 65 & 2.8 & 4.4 \\
\hline
\end{tabular}

Table 5 : Analytical model accuracy

Differences between temperatures computed respectively with the CVM and the $1 \mathrm{D}$ analytical method are low: the mean relative error is less than $2.3 \%$. These value lead to conclude to the interest of the simple 1D semi infinite approach which gives a good description of the preform surface temperature variation versus the heat transfer coefficient for times close to $7 \mathrm{~s}$.

\subsection{Heat transfer coefficient computation}

Now, using the 1-D approach and surface temperature values extracted from each interest zones, we processed to the heat transfer coefficient identification minimising the total relative difference between experimental and temperature computations, assuming a constant environment temperature. We have superimposed (figure 6) the measured and computed variation of the surface temperature for each zone along the preform height. These curves correspond to an air flow temperature equal to $20{ }^{\circ} \mathrm{C}$ at the beginning of the cooling step, after $20 \mathrm{~s}$ 
heating and $10 \mathrm{~s}$ of equilibrating phase. This air flow temperature was measured with shielded iron-constantan thermocouples as shown on figure 1 (two thermocouples are visible near the perform); compared to the effective duration (for the computation of $h_{c}$ ) of the cooling phase, no significant variation was observed on this temperature, in fact equal to the ambient temperature of the laboratory during the experiments. The computation of the heat transfer coefficient was, then, done for a cooling time of $7 \mathrm{~s}$ according to the trends viewed on the figure 5 (for this specific time the $1 \mathrm{D}$ model is valid). The difference between measured and computed values is very low : minor than $2{ }^{\circ} \mathrm{C}$, around $110^{\circ} \mathrm{C}$.

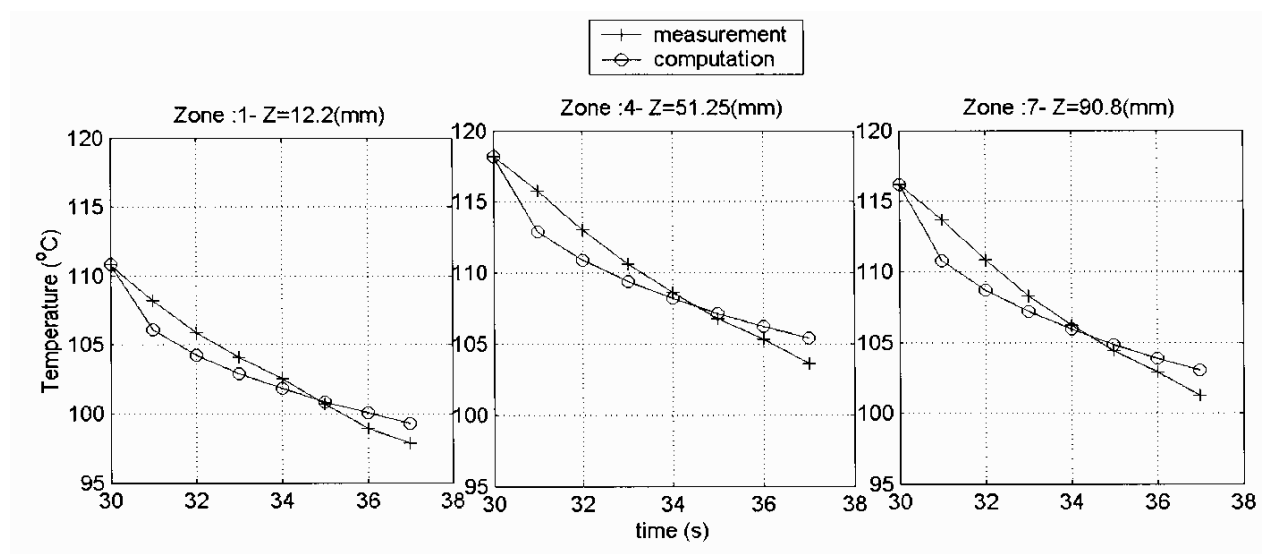

Figure 6. Comparison between measured and computed preform temperatures

The sensibility to the air flow temperature is plotted below : variations of the heat transfer value corresponding for each air temperature. On figure 7, the convective heat transfer coefficient is plotted. We saw that variations of the air flow temperature tend to present high variations in the computation of the heat transfer coefficient. On figure $7,20^{\circ} \mathrm{C}$ is a measured temperature and due to the difficulty to get accurate measurements on this air temperature (intrusive effect of the temperature probe in the flow, recirculation zones), only the effect of a presumed variation around $20{ }^{\circ} \mathrm{C}$ was reported for observed air temperatures in industrial workshops: $15^{\circ} \mathrm{C}$ to $\sim 40^{\circ} \mathrm{C}$. Then to keep the same cooling profile than for an air temperature of $20^{\circ} \mathrm{C}$ (Fig. 6), the new heat transfer coefficient for an air temperature of $40{ }^{\circ} \mathrm{C}$ must increase (by analogy with the Newton law of cooling: $\mathrm{q}=\mathrm{hc}$ (TsurfaceTair), for $q$ assumed to be a constant and Tair increased, $h$ is increasing too); in this case, that can be possible only by increasing the flow velocity as it can be shown with classical convection correlations. It reveals here the importance of the air flow temperature input data in order to increase the accuracy of the heat transfer computation. 


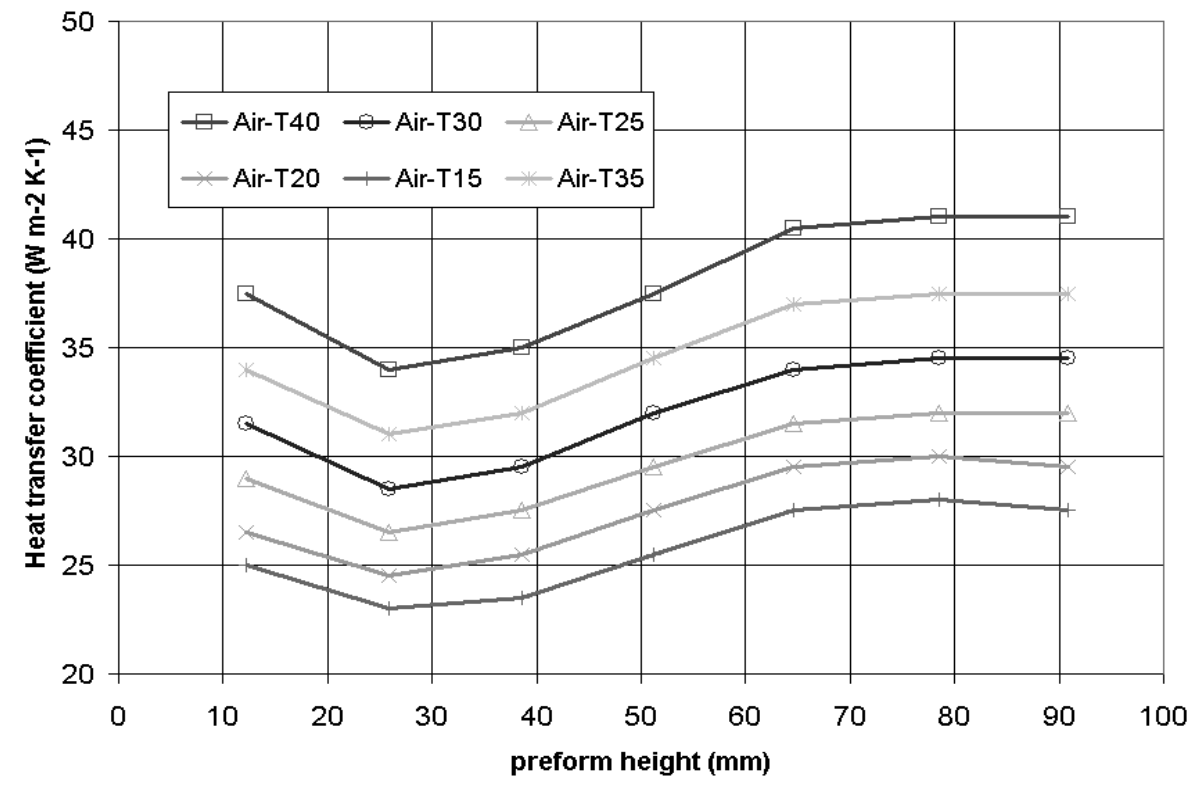

Figure 7. $h_{c}$ computation versus the air temperature value (sensibility analysis)

\section{Heat transfer computation from air flow velocity measurement}

This second method is based on the air flow velocity measurement near the preform. Due to the narrowness of the space between the lamps and the oven (less than $10 \mathrm{~cm}$ ), an ANS Snelco hot wire anemometer with a speed range of $0-30 \mathrm{~m} / \mathrm{s}$ was used at different points along the preform height and for a same level two locations were used as shown on the figure 8 , the distance between the sensing part of the anemometer and the preform was equal to $10 \mathrm{~mm}$ for the two locations and for the front position, $35 \mathrm{~mm}$ from the outlet slits respectively. For each location, several measurements of the air speed were made; at last the average value of the speed for all the measurements of a same level was computed due to the fact that the Plastirad software can only take into account an average hc coefficient versus the height of the preform.

Measurements were performed lamps switched off at the ambient temperature $\left(20^{\circ} \mathrm{C}\right)$ because of the high radiative heat flux from the halogen lamps during the heating stage.

Using the air velocity measurement, we computed the heat transfer convective coefficient $h_{c}$ with the Nusselt number, taking into account air thermophysical properties at the ambient temperature $\left(20^{\circ} \mathrm{C}\right)$. 


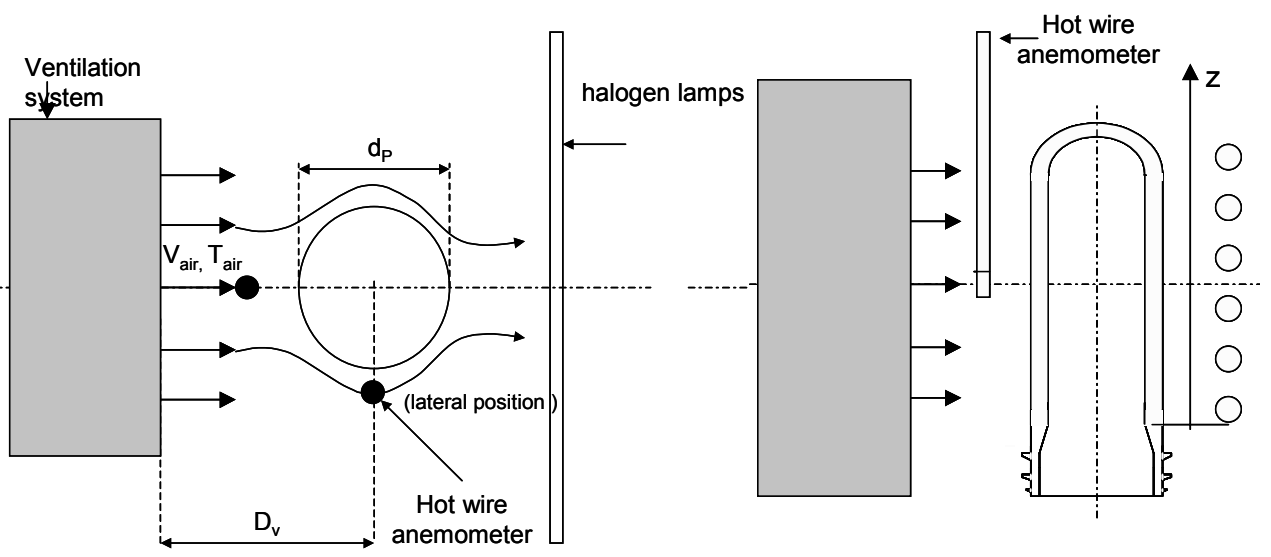

Figure 8. Anemometer set-up description. Left: upper view, right: front view

\subsection{Computation of the convective heat transfer coefficient}

The Reynolds number $\mathrm{Re}=\mathrm{V} \cdot d_{p} / \mathrm{v}$, where $\mathrm{V}$ is the air velocity , $d_{p}$ the characteristic length of the air flow : here, the preform diameter $\left(d_{p}=25.5 \mathrm{~mm}\right)$ and $v$ the air Kinematic viscosity. In our case, the air velocity varied between 1.5 to 5 $\mathrm{m} . \mathrm{s}^{-1}$ (the lowest part of the scale of our anemometer). Then the Reynolds number was defined by the following interval: $4000<\operatorname{Re}<10000$, so we assumed that the air flow was turbulent and used, in a first approach (because in this particular situation, the flow was not a uniform flow), the Hilpert correlation from the literature (Incropera et al., 2002) giving the Nusselt number versus Reynolds and Prandtl corresponding to this particular configuration :

$$
N u=0.193 \cdot R^{0.618} \cdot \operatorname{Pr}^{1 / 3} \text { and } \bar{h}=\frac{N u \cdot \lambda_{\text {air }}}{d_{p}}
$$

Finally the air velocity measurements and the corresponding heat transfer distribution along the preform height are plotted on figure 9 .

These results show a characteristic variation due to the specific ventilation system we used and a high measurement dispersion (in accordance with metrology advises, the uncertainty bars for the computation of $h_{c}$ are twice the standard deviation of the same parameter): the uncertainty for the $h_{c}$ coefficient is equal to 29 $\%$ for the maximum value and $23 \%$ for the minimum one; but we want to mention here that it was particularly difficult, inside the oven environment, to visualize air flow using smokes or other techniques due to the halogen lamps and electrical wire proximity. 


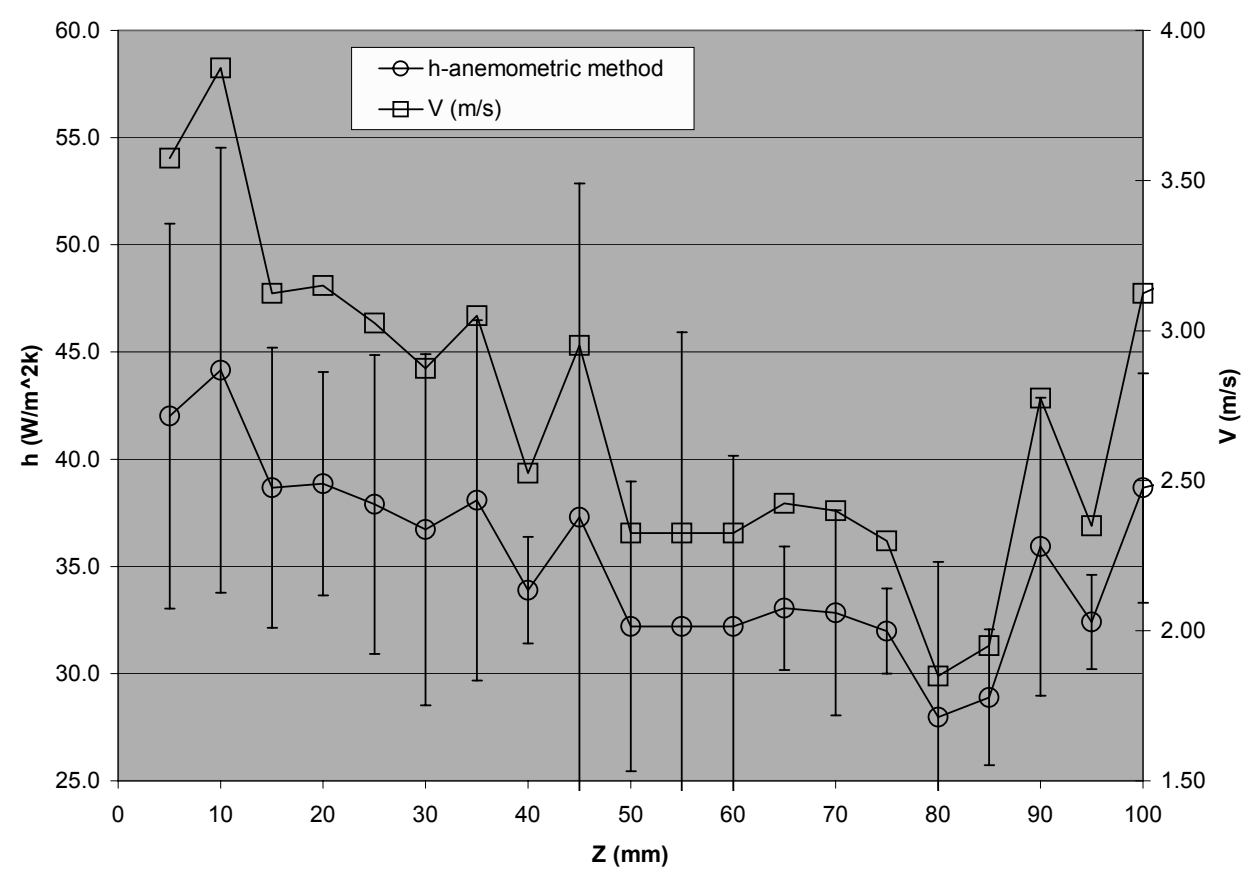

Figure 9. Air speed velocity measurement and computation of $h_{c}$

\subsection{Comparison of the two methods.}

To compare the two methods, we have superimposed results of the $h_{c}$ computations. Results obtained by the thermography method represent the $h_{c}$ average value obtained for different presumed air temperatures resulting of the sensibility analysis around air temperature of $20^{\circ} \mathrm{C}$. The corresponding uncertainty bars results also from twice the standard deviation of these values (figure 10).

We note, here, that the two methods lead to a same heat transfer coefficient scale value. However the distribution along the preform height is different. We note a large uncertainty of the two methods due to the high non uniformity of the air flow and the temperature variation inside the air flow. Also, the 1D method tends to integrate and to smooth the values of $h_{c}$. 


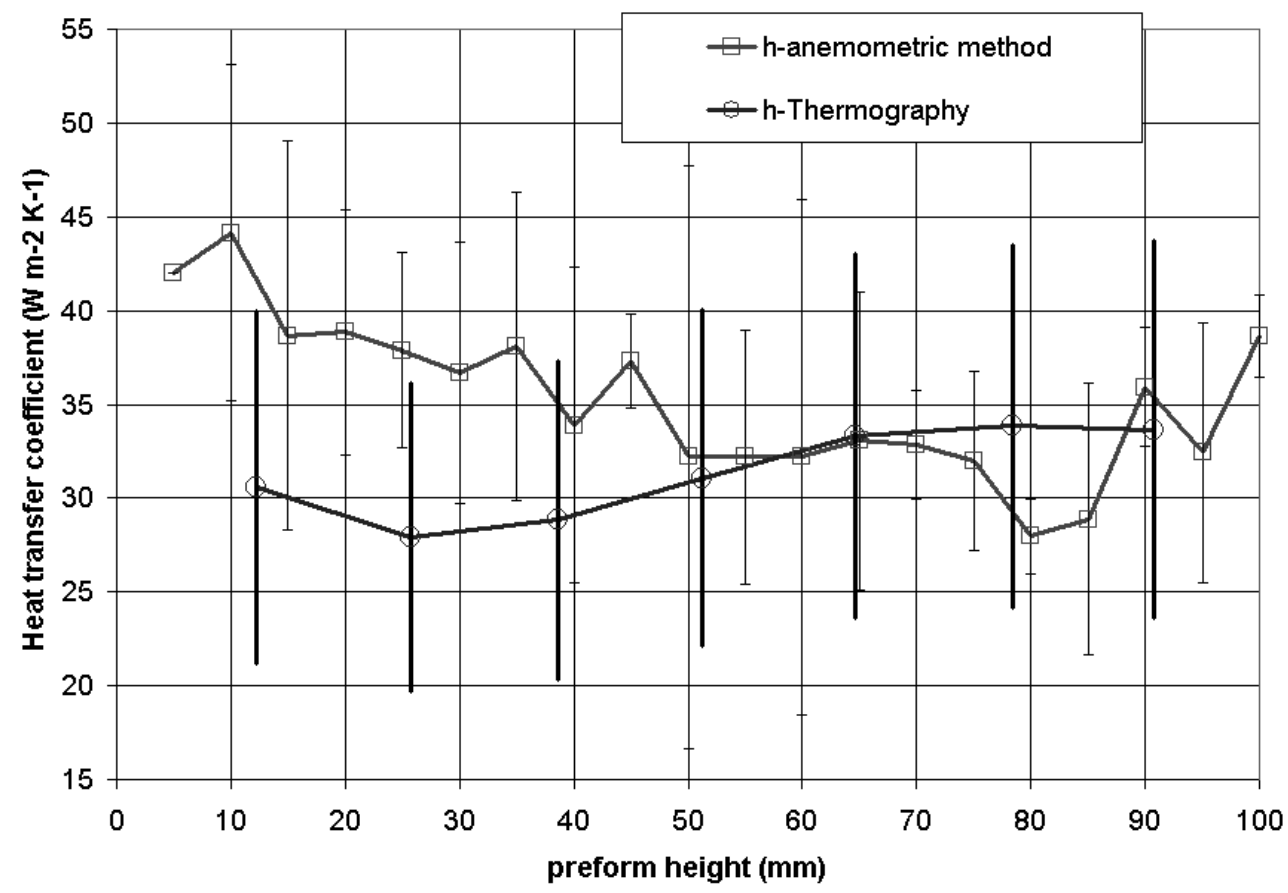

Figure 10. Comparison of $h_{c}$ along the preform height obtained by the two methods

\section{Conclusion}

In this paper, we developed different methods to estimate the heat transfer coefficient along the preform height coupled with an air cooling system. At first, we analysed the environment participation inside the oven and showed that, despite all the reflectors inside the oven, the participation of the preform environment was negligible in a first approach. Then, we developed a specific analysis involving IR thermography using images recorded all along the preform height and focused this analysis on the cooling step in order to simplify the problem. A 1D analytical model was used to compute the preform surface temperature distribution versus the heat transfer coefficient. In order to validate this computation, we compared the accuracy of the 1D model with a CVM. This comparison leads to conclude that temperature discrepancies are less than $10 \%$. Finally, for each zone of the preform, we measured a local and average heat transfer coefficient $h_{c}(z)$. The comparison between the thermographic measurements and values computed with a classical anemometric method provided heat transfer coefficients in the same range. However, we noted that the two methods presented a large uncertainty. The method based on the thermography seems very sensitive to the air temperature and takes into account all the components of the air 
flow that could explain these discrepancies. So, due to the relative proximity of the heat transfer coefficient obtained by these methods, we will emphasize on the interest of the thermographic method which deals with all the preform height and limits the measurement time. These measurements were also tested successfully on industrial machines and led to realistic values of $h_{c}$ which were in the range of $35-60 \mathrm{~W} / \mathrm{m}^{2} . K$, range very close to our laboratory results but smaller than the values found by (Lebaudy, 1989): $\sim 80 \mathrm{~W} / \mathrm{m}^{2} . \mathrm{K}$. These values were obtained with an iterative procedure and a 2D axisymmetric finite difference method. In order to confirm potentiality of our method, it would be interesting to reproduce this comparison dealing with a bigger heat transfer coefficient range to test the effect of the variation of $\mathrm{h}_{\mathrm{c}}$ on the quality of this specific process. Also, to increase the accuracy of the thermographic method, a particular attention will be attached to the air flow temperature measurement enhanced by the radiative environment and intrusive action of the thermocouples. In the same way, if a real reference method, based on a more realistic correlation for jets, is needed to "calibrate" the thermographic method, a work has to de done to provide a better description of the flow inside the oven; for that, a CFD software such as FLUENT could improve our knowledge of the ventilation system. At last, we are currently working on a specific ray tracing method devoted to accurate radiative transfer computation inside the infrared and also to optimise the position of the IR camera to be less sensitive to reflections.

\section{Acknowledgements}

The authors would like to thank The Nestlé Waters Company for participation in this work, and specially G. Denis for his technical support.

\section{Bibliography}

Rosato D., “ Blow molding handbook, Hanser Publishers, 1989.

Monteix S., "Modélisation du chauffage convecto radiatif de préforme thermoplastique pour la réalisation de corps creux, $\mathrm{PhD}$ thesis - ENSMP, 2001.

Weinand D., "Modellbildung zum Aufheizen und verstrecken beim thermoformen", Dissertation an der RWTH -1987.

Siegel R., Howel J, “Thermal Radiation Heat Transfer”, Third Ed Hemisphere publishing Corporation, 1992.

Monteix S., Schmidt F., Le Maoult Y., Denis G., Vigny M.,"Comparison between a numerical model and an experimental approach of preform infrared heating - recent results", International Conference on Heat Transfer-ASME-Australia-may 2001.

Hajji N., Spruiell J.E., "Radiation pyrometry on semitransparent sheets I:Gray Media”, Polymer engineering and science, vol. 34, no 2, 1994.

De Vriendt A.B., "La transmission de la chaleur ", vol.1, tome 1, Gaétan Morin, Chicoutimi Québec, 1984 
Incropera F.P., DeWitt D.P, Fundamentals of Heat and Mass Transfer, fifth ed. - John Wiley2002.

Lebaudy P., “Etude et simulation de la répartition des températures dans un cylindre creux de P.E.T soumis à un rayonnement infrarouge, $\mathrm{PhD}$ thesis, Université de Rouen-1989. 